\title{
Efficacy of a metacognitive writing-to-learn exercise in improving student un- derstanding and performance in an engineering Statics course
}

\section{Dr. Saryn R Goldberg, Hofstra University}

Dr. Saryn R. Goldberg is an Associate Professor of Mechanical Engineering in Hofstra University's School of Engineering and Applied Sciences. Dr. Goldberg received her Sc.B. in Engineering with a focus on materials science from Brown University, her M.S. degree in Biomedical Engineering with a focus on biomaterials from Northwestern University, and her Ph.D. in Mechanical Engineering with a focus on biomechanics from Stanford University. At Hofstra she teaches courses in mechanical engineering, materials science and biomechanics. In addition to her research in engineering education, Dr. Goldberg studies the biomechanics of human movement, focusing on gait rehabilitation. She is a member of ASEE, the Society of Women Engineers and the American Society of Biomechanics.

\section{Dr. Jennifer Andrea Rich, Hofstra University}

Jennifer A. Rich is Associate Professor of Writing Studies and Composition at Hofstra University. She has published widely in writing studies, film, Shakespeare, and popular culture. She has recently published a book-length guide to the philosophy of Theodore Adorno.

\section{Dr. Amy M. Masnick, Hofstra University}

Dr. Amy Masnick is an Associate Professor of Psychology at Hofstra University. Dr. Masnick received both her B.S. and Ph.D. in Human Development at Cornell University. At Hofstra she teaches courses in introductory psychology, research methods, cognitive psychology, and child development. Dr. Masnick is interested in conceptual development, reasoning about science and number in children and adults, and in science and engineering education. 


\section{Efficacy of a metacognitive writing-to-learn exercise in improving student understanding and performance in an engineering Statics course}

\section{Introduction}

In science classrooms at both the high school and college level, it is becoming increasingly commonplace to use writing to strengthen students' conceptual understanding of the course content. Since the 1980s, studies of student writing in science classes have shown that conceptual knowledge is increased and concretized through multiple modalities of writing, such as journaling, summary or explanation, laboratory reports, and news articles. $1,2,3,4$.

What is less clear is the relationship between integration of writing and increased competency in non-conceptual areas of science, or in areas where concept and application (quantitative) are both required. In these circumstances, writing is used not so much to demonstrate knowledge as to achieve an understanding of the students' own learning process. Writing-to-learn assignments in these contexts usually attempt to make the student aware of his or her learning issues, asking the student to reflect on what he or she may not understand. The modalities for doing so are various: students have been required to write step-by-step explanations of their problem-solving; ${ }^{5,6,7}$ they have been asked to explain how to do a problem to a relative neophyte in the class; ${ }^{8}$ and they have been encouraged to embed literary modes in their problem-solving narratives (e.g. explaining how to solve stoichiometric equations through baking analogies). ${ }^{9}$ While these approaches have resulted in some anecdotal evidence of increased understanding on the part of students, there is as of yet limited evidence that these modes actually lead to better student performance in traditional exams and course grades.

In more recent work, one mode that has shown promise is the integration of revision into writing-to-learn assignments. This incorporation of revision has been predominantly practiced in math and chemistry classroom contexts. Revision can take different forms; sometimes, revision is simply having the student reexamine what he or she has written after instructor input and correct his or her initial written response to a question or questions. ${ }^{8,9,10,12,13}$ Other modes of incorporating revision include sharing written work with peers and rewriting based on their feedback. ${ }^{8,12}$ Still others have students revisit old problems later on in the semester (after a midterm or final) and rewrite their answers in light of new knowledge gained during the semester. $^{8,9,10}$

There is significant anecdotal evidence that revision helps students achieve higher metacognitive understanding of the problems about which they write. ${ }^{10,11,12}$ In one study that examined the integration of multi-modal writing exercises into a chemistry class, students were asked to write a description of a chemistry concept to a "non-expert reader." 9 The premise behind this assignment was that students' understanding of science would be deepened if they were actively engaged in explaining concepts in writing to a neophyte audience. As the authors note, "the tasks are designed to allow students to experience a 'write, react, revise' scenario . . " 9 One task 
required students to write an explanation of stoichiometry to a younger group of students unfamiliar with Chemistry. This concept was difficult for students to articulate clearly to their younger audience. They received feedback that pinpointed areas of confusion on the part of their audience. Their task was to then revise their answer in order to respond effectively to the feedback that they received. The authors note that in general the second drafts for this task were more detailed with regard to the conceptual underpinnings of the subject. The study found that there were "positive correlations" between engaging in multi-modal writing tasks and end-ofunit performance.

Other studies have also focused on revision as a potentially important component of students' metacognitive competence. 9, 10,11,12 For example, in another study also involving students in Chemistry, researchers had students embed a multi-modal writing task at the end of each unit, as well as a unit assessment. ${ }^{9}$ These writing tasks differed depending upon the context of the course and the particular instructor's goals. But all of them had in common a "write, react, revise" component, forcing the student to revisit their writing task after input from a peer or instructor or both. Although several different instructors participated in this study, the writing interventions were kept uniform in order to ensure that revision was a central piece of the students' work. The researchers concluded that this revision step was instrumental in helping students understand and recognize limitations in their own understanding. ${ }^{6,8,9,10}$ Some studies also observed that writing to a neophyte (non-expert) audience was an important component to the growth of their understanding. 9,12

Another element of our writing intervention that may encourage metacognition is requiring students to formulate questions about what they do not understand (see description of methods below). Most writing-to-learn interventions, as we have seen above, require students to provide a step-by-step rationale for their problem-solving or to answer questions about concepts under examination. The task of having students formulate questions about their own work - and what they find difficult or confusing - is virtually absent from current writing-to-learn heuristics in use. It is our belief that the requirement to frame a question compels students to take a bird's eye view of their own thinking process and to attempt to identify conceptual gaps in their understanding. This cognitive work necessitates thinking about their own thinking: this act is what defines the metacognitive enterprise. It may well be that the two actions togetherformulating questions coupled with revising what they have written-will lead students to higher performance in Statics and possibly other engineering and science courses.

In the present study we implemented a writing intervention that we believed would lead to improved student understanding and performance in an engineering Statics course. The work presented here is part of a larger study in which we introduced a writing-prompt intervention into the PI's Statics class over the course of five semesters. We made changes to the writing prompt as we learned more about how to effectively implement it, such that we had three successive iterations of the prompt. This paper focuses on the results of the third iteration, with the first two iterations and their results having been reported previously. ${ }^{13}$ This third iteration of the writing prompt included a revision component and asked students to formulate questions in writing based on their perceived misunderstanding about Statics concepts under review. 


\section{Method}

Students who took the lead author's Statics course were participants in this study. In this paper, we focus on the 66 students who were in three sections across two semesters, who participated in the intervention described below (a total that excludes the 5 students who were either taking the course for the second time or who did not complete all the work, earning an Incomplete in the course). These students were compared with the 40 students who took the same course in two sections across two semesters a few years earlier (excluding the 8 students who were taking the course for the second time or who earned an Incomplete). The course content and the grading were substantively the same, except that the students in the pre-intervention semester did not complete the intervention questionnaires or get feedback from the instructor via this medium.

We asked students in the intervention semesters to respond to a writing prompt (described below) for one specific problem (out of three to five total problems) on each of 10 homework assignments per semester. Through student surveys and interviews, we assessed the effect of responding to these prompts on students' perceptions of their understanding of Statics concepts and on students' ability to identify when they did not understand a concept. We also assessed whether the inclusion of the writing prompt improved student performance on exams.

Homework was assigned approximately every 1.5 weeks in the lead author's Statics class. The skills required to solve the problem selected on each assignment directly correlated to those needed to solve a problem on the upcoming exam. Performance on the written portion of the homework was worth $20 \%$ of the homework grade to motivate completion of the assignments, and all work was graded by the instructor using an algorithm that was shared with the students. The grade was based on whether the student completed the assignment in a thorough manner, with what was perceived to be a full effort. For example, in one portion of the prompt, students were asked to describe what confused them about the problem in at least three sentences to encourage them to think and respond with specific ideas and in a detailed manner. Answering with three thoughtful sentences would earn 3 out of 3 possible points, answering with a single sentence or little specificity would earn 2 points, and answering with just a few words might earn 1 point.

All activities associated with the writing prompts took place in class, such that students only missed a written assignment if they did not attend class or did not turn in the homework. After students solved selected engineering problems at home, they were asked to describe in writing in class any confusion they had about the concepts or computations required to solve the problem. They were also asked to write down a question they could ask that could help them clarify their confusion. The professor then demonstrated the problem solution in class as students corrected their own work and encouraged students to ask any of their written questions. Following this, students revisited their initial written response to the prompt and then described their revised understanding of the problem, having now had the solution to the problem explained to them and potentially having had some of their questions answered. Students were also given space to pose more questions to the professor. Finally, the instructor collected the questionnaires, and then provided additional individualized written feedback returned to students during the next class period, indicating whether students' understanding of the reason for their error(s) was accurate and responding to any unanswered student questions. 
At the end of the semester, student surveys were administered in class to learn more about students' perceptions of the value of the additional writing assignments. Students answered 11 multiple-choice questions, such as:

Writing out questions that I had about a problem in the first part of the in-class questionnaire made it

a) a lot easier to identify concepts/computational steps with which I had trouble.

b) somewhat easier to identify concepts/computational steps with which I had trouble.

c) neither easier nor harder to identify concepts/computational steps with which I had trouble.

d) somewhat harder to identify concepts/computational steps with which I had trouble.

e) a lot harder to identify concepts/computational steps with which I had trouble.

Students were also given space for open-ended feedback about their experiences with the questionnaires. In addition, 10 student volunteers were interviewed about their experiences with the writing prompt.

For the intervention and control semesters we compiled anonymous pre-requisite course grades (in math and physics) and high school GPA data so that we could compare cohorts across semesters. In addition, for the 51 students who took the course in Fall 2014, we asked for permission to access identified student pre-requisite grades and high school GPA.

\section{Results}

Our main dependent outcome was course performance, assessed by students' final course grades. The statistical data indicate that final course grades were higher in the intervention semesters as compared to the control semesters, as seen in Table 1.

As a result of our experience implementing past iterations of the writing prompt, we had significant concerns about student compliance. To address this concern, all of the questionnaires and surveys were completed during class. As a result, those students who did not complete the questionnaires either did not complete the homework (and thus could not discuss where they had difficulties in completing it), or did not attend class. We found that students completed $87.4 \%$ of the 10 intervention assignments. In addition to examining whether students completed the intervention questionnaires, the instructor also graded the questionnaires based on how thoroughly they were completed (as described in the Method), and students averaged a grade of $81.7 \%$ on that measure. Students' grades on the questionnaires were strongly correlated with their final grades in the course, $r=.70, p<.001$.

We used anonymized high school GPA and prerequisite math and physics course grades, unmatchable to specific students, to examine whether there were overall cohort differences in preparation for the Statics course, only including those students we included in our analyses. Some schools weight honors courses so they can be higher than a 4.0 grade, but we forced all grades to a 4.0 maximum. We found significant differences in high school GPAs between those in the control semesters and those in the intervention semesters, with those in the intervention semesters having a higher average high school GPA. Similarly, those in the intervention 
semesters had, on average, higher grades in both the math and physics prerequisites for the Statics course. Details are shown in Table 1. Note that the precise number of students in each analysis differs because a few students earned prerequisite credit with AP scores, and we did not have high school GPA information for some students.

Table 1. Final grades in Statics, high school GPA, physics prerequisite, and math prerequisite grades by intervention condition. While the final grade in Statics did show a statistically significant increase in the intervention semesters as compared to the control semesters, there was also a statistically significant increase in measures of course preparation, indicating a potential cohort effect.

\begin{tabular}{lccccc} 
& \multicolumn{2}{c}{$\begin{array}{c}\text { Control } \\
\text { semesters }\end{array}$} & \multicolumn{2}{c}{$\begin{array}{c}\text { Intervention } \\
\text { semesters }\end{array}$} & t statistic \\
\hline $\begin{array}{l}\text { Final } \\
\text { grade in }\end{array}$ & $\mathrm{N}$ & Mean (SD) & $\mathrm{N}$ & Mean (SD) & \\
$\begin{array}{l}\text { Statics } \\
\begin{array}{l}\text { High } \\
\text { school }\end{array}\end{array}$ & 40 & $\mathbf{7 7 . 8}(15.3)$ & 66 & $\mathbf{8 4 . 6}(10.1)$ & $t(104)=-2.79, p=.007$ \\
$\begin{array}{l}\text { GPA } \\
\begin{array}{l}\text { Physics } \\
\text { prerequisite } \\
\text { grade }\end{array}\end{array}$ & 38 & $\mathbf{2 . 6 1}(1.03)$ & 60 & $\mathbf{3 . 1 0}(.71)$ & $t(91)=-2.51, p=.014$ \\
$\begin{array}{l}\text { Math } \\
\text { prerequisite } \\
\text { grade }\end{array}$ & 35 & $\mathbf{2 . 5 0}(1.11)$ & 59 & $\mathbf{3 . 5 9}(.37)$ & $t(96)=-2.80, p=.006$ \\
\hline
\end{tabular}

We also asked students in the intervention classes to fill out a survey near the end of the semester to self-assess the value of the intervention in their learning. There were eleven multiple-choice questions on the survey. Responses on two of the questions were significantly correlated with final grades in the course. Specifically, students who responded that "Writing out questions that I had about a problem in the first part of the in-class questionnaire made it easier to identify concepts/computational steps with which I had trouble" were more likely to have a higher grade in the course $(r=-.26, p=.042)$. Similarly, students who responded "When I don't understand something in class, I generally find that it easy for me to formulate the questions I need to ask to help me understand" tended to have a higher grade in the course $(r=-.33, p=.011)$.

In the Fall 2014 semester, we asked students for permission to access their prerequisite and admissions data by student ID number so that it could be matched. Of the 51 students who completed the course that semester, 44 students gave permission for us to access their prerequisite and admissions information after the Statics course was completed. We used a regression model with grades on the intervention questionnaires, answer on the survey about how easy it is to formulate questions (the survey question most strongly correlated with final grades), high school GPA, math prerequisite grade, and physics prerequisite grade as predictors. The full model was significant, but only two predictors affected the outcome: grades on the intervention, 
and grades in the math prerequisite. Thus, the final model included only these two predictors. This led to a model with $R^{2}=.698$, adjusted $R^{2}=.683, F(2,42)=46.19, p<.001$ (note this model excluded one student who earned AP credit for the math prerequisite and did not have a grade). The average final course grade of those who gave permission for us to see their prerequisite grades and who had a grade for the math prerequisite was $86.51, S D=7.72$, a little higher than the course average for all students that semester. The final regression model is:

Final grade $=42.23+31.08 *$ intervention grades $+5.482 *$ prerequisite math grades Note that the intervention grades are from $0-1$ and the math prerequisite grades are on a 4.0 GPA scale. The standardized beta coefficients are 6.31 and 6.83 , respectively, and both $p$-values are $<.001$. In sum, this model indicates that fully completing the intervention questionnaires and math background independently contribute to explaining the variance in final course grades.

At the end of the semester, students filled out surveys that evaluated their experience completing the homework questionnaires. Some also participated in interviews with Drs. Rich and Masnick in which they discussed their views of the efficacy of the questionnaires in improving their comprehension of material.

Student self-reports of the value of the questionnaires showed that the majority of students believed them to be valuable. In answering the surveys, $72.7 \%$ of students said that completing the in-class questionnaires made them a lot more likely or somewhat more likely to take time to think about what confused them about the problem. Similarly, $75.8 \%$ of students said that completing the in-class questionnaires made it either a lot easier or somewhat easier to identify what confused them about the problem. Further, $71.2 \%$ of students said that they believed that completing the questionnaires has and would continue to either significantly or somewhat improve their performance on exams in the course.

In the open-ended portion of the surveys, some students noted that the writing intervention allowed them to ask questions that they might not ordinarily have asked in class, along with allowing them to "think about what you know and what you need to work on." They also noted that this venue provided students with an alternative to asking their question(s) in class. If they felt unsure about the value of their question(s), they were able to ask it (them) in a way that did not interrupt class time and was more private.

In the interviews a similar sentiment was expressed. Students reported that the questionnaires allowed them to think more carefully about the way in which they were solving problems and to review or revise their approach when needed. This second look gave them the ability to catch more details, and to be more confident in their overall understanding of the problem. Yet another student remarked that the questionnaires stretched his thinking. It allowed him to think more thoroughly about the question, thus pushing him to think a bit outside of the box.

Finally, another student noted that she thought using writing might help her in her more advanced engineering courses. In her interview, she indicated that the intervention seemed to provide a more organized context for her learning, which she missed in some of her more advanced engineering classes. Although she was not a big fan of the writing requirement in Statics (because she felt relatively confident in her ability in this class), she did think that writing 
would help in classes that require better organizational skills or where the pedagogical approach is not as clear as it was in her Statics class.

A few students felt that the questionnaires were not helpful to them because they were already doing well in the course and did not struggle with the concepts. One student, for example, noted that he understood how the method could be useful for others who struggled more with Statics, and how it might be useful for him in other more challenging courses, but that he didn't feel it helped him directly in the Statics course. In sum, the students saw the value of the methodology, and those who had to work hard to master the Statics concepts tended to note that they found this intervention helpful to their learning.

\section{Discussion}

The results show that course grades were higher for students who participated in the intervention than for those who were in the control semesters, but it is important to note that prerequisite grades were also higher for the students in the intervention group, evidence of a potential cohort effect. Math preparation does explain a sizeable percentage of the final grade, so the improvement in math preparation likely explains a large part of the improvement in course performance. One way to address this concern in future study designs is to work with multiple sections within the same semester from within the same cohort, having some sections complete the intervention, and others serving as control groups.

However, grades on the intervention questionnaire (and simple completion of the questionnaire) were an independent predictor of final grades in the course, above and beyond prerequisite grades. This relationship suggests that students who put effort into the questionnaires (that is, those who took the intervention seriously and gave it full attention) benefited from it by performing better in the course. It is also possible that conscientious students were more likely to put a good effort into the questionnaires and more likely to do well in the course. It may also be that some combination of these two factors led to the outcome. One way to address this concern in future designs might be to have a separate measure of conscientiousness. However, it is impossible to tease out fully, as conscientiousness is always a factor in course success.

Survey and interview responses suggest that students found aspects of the questionnaire interventions useful. There were largely positive ratings on the utility of questionnaire, and some students noted in their open-ended responses that they felt as though it added to their metacognitive understanding. One very enthusiastic student even said the intervention inspired her to use this evaluation technique in her other courses.

These positive student comments indicate that students seem receptive to this kind of pedagogical approach. We specifically designed this intervention such that student efforts were directed towards an activity that is a natural part of the problem-solving process (identifying areas of confusion) and would hopefully be perceived to be of benefit to them. Student perception of the task's efficacy is an important factor in its ability to be implemented successfully, since whether students appreciate the utility of an exercise is a large factor in determining whether they will put effort into it. 
The range of positive student comments about the questionnaire also suggests that this reflective approach is helpful to at least some students. Student responses to surveys and interviews suggest that they perceived that completing the written homework not only helped their conceptual understanding but also their computational understanding. For example, one student, in response to the interview question "Do you feel that you achieved a fuller understanding of the concept being tested by completing the questionnaires?" replied, "I'd say the little details, when doing computations, got down more, more processed, because I had to think of it, think about questions I had. More the small details." This observation suggests that students were aware of occasionally revising or rethinking their approach to solving problems computationally. This kind of computational metacognition inspired by a writing intervention is unique in the context of implementing writing-to-learn heuristics in a science class. As we noted above, these heuristics usually encourage greater conceptual understanding without necessarily aiding the students in their computational competence.

One critical goal of future work is to see if it is possible to identify the traits in a learner who is most likely to benefit from this kind of intervention. The correlation between grades in the course and students' perceived ability to formulate questions about tasks they were confused about suggests the weakest students may not have benefited from the questionnaires because they did not know enough to begin to ask questions about the problems. Perhaps such students would benefit more from a more targeted, scaffolded questionnaire that guided them toward understanding the concepts well enough to ask more effective questions.

One unexpected finding was that some students said that they found the intervention useful because it gave them an unobtrusive means for asking a question, one that didn't draw attention to themselves or take up limited class time. They noted that they appreciated this direct channel of communication with the professor. This is an important discovery that may have implications for how engineering classes should structure the modalities available for students to ask questions. This also may be important for some female students who may be more reticent than their male colleagues to pose questions in class, as was suggested by two survey responders. ${ }^{i}$

The revision step of our intervention allowed students to clarify their new understanding of the problem under consideration and also to reassess the reasons for their initial confusion. In this way, it closed the loop for them metacognitively. The prompt for students to articulate and ask their own questions required an even higher level of self-assessment than simply answering questions asked by the instructor. Because there were multiple components to the intervention (formulating questions about the material, assessing one's understanding, revising beliefs, and

\footnotetext{
${ }^{\mathrm{i}}$ Although only two students expressed this concern in interviews, there is evidence that female and male students in engineering approach classes and course material differently, and that female students may be less confident than male students. See, for example, C.M. Jagacinski, "Women engineering students: Competence perceptions and achievement goals in the freshmen engineering course” Sex Roles 69(11-12): 644-657, 2013; Richard M. Felder, et al., "A longitudinal study of engineering students performance and retention: Gender differences in student performance and attitude" Journal of Engineering Education 84(2): 151-163, 1995; and Vrcelj, Z and S. Krishnan, "Gender differences in student attitudes toward engineering and academic careers" Australasian Journal of Engineering Education 14(2): 43-56, 2008.
} 
asking for and receiving feedback from the instructor), it is unclear what aspect may have lead to any benefits, or if it was a combination of the different components. Future research is needed to tease apart some of these factors.

When designing our intervention, we wanted to be conscious of the amount of time it would take for a faculty member to assess student work and whether the time spent would be valuable to the faculty member. One benefit of the approach we took is that the questionnaires provided the instructor with useful information as to what concepts students were struggling with, and it offered an easy mechanism for directly answering individual students' questions when grading their assignments - both of which are of value to the faculty member, in addition to the students. While responding to the questionnaires did take time, changes could be made to make this approach more easily scalable to larger courses. One approach would be to respond to the questionnaires electronically. The professor could formulate answers to some of the most commonly asked questions and write descriptions of oft-misunderstood topics that could be edited in response to individual student questions and stated confusions. The PI found that the most time consuming part of assessing the questionnaires was reviewing each student's written solution to the homework problem under consideration to see if they had correctly and completely identified what it was they misunderstood about the problem. If more significant time-savings were needed, a professor teaching a large class could potentially forgo the step of reviewing student work and only respond to the questionnaire, clarifying misconceptions demonstrated by the students' responses to the prompt and answering any questions posed.

In summary, while cohort effects obscured our ability to quantify the influence of our intervention on student performance, many students found the writing exercise to be of value in helping them to better understand and resolve their confusion about Statics concepts. Future work will focus on identifying the types of students who have the most potential to benefit from this type of writing intervention and modifying it to be of more value to students who have difficulty articulating their own confusion and formulating their own questions.

\section{Acknowledgement}

This work was supported by the National Science Foundation's Research Initiation Grants in Engineering Education under award No. 1137009. Any opinions, findings, and conclusions or recommendations expressed in this material are those of the authors, and do not necessarily reflect the views of the National Science Foundation. The authors thank Irina Fanarraga for assistance with data entry.

1. Emig, J. 1977. Writing as a mode of learning. College Composition and Communication 28(2): 122-128.

2. Linda Flower, et al. 1981. A cognitive process theory of writing. College Composition and Communication 32(4): 365-387.

3. Galbraith, D. (1999). Writing as a knowledge-constituting process. In D. Galbraith \& M. Torrance (Eds.), Knowing what to write: Conceptual processes in text production Amsterdam: Amsterdam University Press.

4. Holliday, W., et al. 1994. The reading-science writing-learning connection: Breakthroughs, barriers, and promises. Journal of Research in Science Teaching, 31: 877-893. 
5. Hanson, J. H. et al. 2008. Using writing assessments to improve students' self assessment and communication in an Engineering statics course. Journal of Engineering Education. 97(4): 515-529.

6. Kagesten, O., et al. 2006. Supplementary explanations in undergraduate mathematics assessment: A forced formative writing activity. European Journal of Engineering Education, 31(6): 705-715.

7. Porter, M. et al. 2000. Examining the effects of writing on conceptual and procedural knowledge in calculus. Educational Studies in Mathematics. 42: 165-177.

8. Hand, B. et al. 2006. Using writing-to-learn strategies to improve year 11 students' understandings of stoichiometry. International Journal of Science and Mathematics Education. 5: 125-143.

9. McDermott, M. et al. 2013.The impact of embedding multiples modes of representation writing tasks on high school students' chemistry understanding. Journal of Instructional Science. 41: 217-236.

10. Prain, V. 2006. Learning from writing in secondary science: Some theoretical and practical implications. International Journal of Science Education, 28(2): 179-201.

11. Pineda, L. et al., 2000. A model for multi-modal reference resolution. Computational Linguistics, 26(2): 139193.

12. Gunel, M. et al. 2009. Writing for different audiences: effects on high-school students' conceptual understanding of biology. Learning \& Instruction, 19(4): 354-367.

13. Goldberg, S. et al, 2014. The use of writing-to-learn prompts in an engineering statics course to improve student understanding and performance. Conference Proceedings of 121st ASEE Conference, Indianapolis, Indiana. 